RESEARCH

\title{
Dominantly and Recessively Inherited Cornea Plana Congenita Map to the Same Small Region of Chromosome 12
}

\section{Esa Tahvanainen, ${ }^{1,4}$ Aldo Sigler Villanueva, ${ }^{2}$ Henrik Forsius, ${ }^{3}$ Pia Salo, ${ }^{1}$ and Albert de la Chapelle ${ }^{1,3}$}

\author{
${ }^{1}$ Department of Medical Genetics, University of Helsinki, 00014 Helsinki, Finland; ${ }^{2}$ Ophthalmological \\ Clinic, Central Hospital of Moron City, Codigo 65100, Cuba; ${ }^{3}$ The Folkhälsan Institute of Genetics,
} 00250 Helsinki, Finland

\begin{abstract}
Cornea plana congenita occurs in a mild autosomal dominant (CNAl) and a more severe autosomal recessive (CNA2) form. We recently assigned a CNA2 locus to a region on chromosome 12 by linkage analysis and excluded linkage to that locus in two Finnish CNAl families. Here we describe a Cuban pedigree in which 14 members are affected with dominantly inherited cornea plana. By linkage analysis this phenotype was mapped to the immediate vicinity of markers DI2S82 and D12S35I on $12 q$, that is, precisely the same small region ( $3 \mathrm{cM}$ or less) to which CNA2 previously had been assigned. Our results support the existence of at least three genetically distinct forms of cornea plana. It remains to be determined whether recessive and dominant cornea plana are caused by different mutations of a single gene or whether the region in $12 q$ harbors two or more genes whose mutations cause corneal maldevelopment.
\end{abstract}

The classification of cornea plana congenita has been based on inheritance patterns and clinical signs. McKusick's catalog (1994) lists an autosomal dominant form (CNA1, MIM 121400) and an autosomal recessive form (CNA2, 217300). With the recent assignment of a recessive form to chromosome 12q (Tahvanainen et al. 1995a) and the exclusion of that locus as a cause of dominantly inherited cornea plana in two Finnish families (Tahvanainen et al. 1996), the two forms could be proven to be genetically distinct.

Clinical signs shared by the dominant and recessive forms of cornea plana include reduced corneal curvature, indistinct border of corneal limbus, and arcus lipoides at an early age. The two forms are best distinguished from each other by a round and opaque thickening, $\sim 5 \mathrm{~mm}$ in width located centrally. This thickening occurs in most cases of the recessive form but never in the dominant form. Additional anomalies such as malformations of the iris, a slit-like pupil, and adhesions between the iris and cornea are more prevalent in the recessive form (Eriksson et al. 1973).

${ }^{4}$ Corresponding author.

E-MAIL etahvana@helsinki.fi; FAX + 358-0-434 6677.
In this study we describe a newly discovered pedigree from Cuba showing dominant inheritance of cornea plana. By linkage analysis its locus was assigned to the same small chromosome region as CNA2. The result was confirmed by observing an extended conserved haplotype in all known affected individuals in three generations.

\section{RESULTS}

Pairwise lod scores between the disease phenotype (CNA1) and 12 marker loci are shown in Table 1 . No obligate recombinations were observed between CNA1 and markers D12S88, D12S365, D12S316, D12S82, D12S351, D12S322, D12S311, and D12S95. The closest markers with which recombination was observed were D12S319 on the centromeric and D12S327 on the telomeric side, defining an interval of $\sim 4 \mathrm{cM}$. The highest lod score of 6.98 was observed with marker D12S322, and the second highest lod score of 6.20 with marker D12S351. These two markers also displayed the highest lod scores in our previous study of CNA2.

The results of eight-point linkage analysis are shown in Figure 1. With marker D12S81 as an 
TAHVANAINEN ET AL.

\begin{tabular}{|c|c|c|c|c|c|c|c|c|c|c|c|}
\hline Locus & 0.00 & 0.001 & 0.01 & 0.05 & 0.10 & 0.20 & 0.30 & 0.40 & $\mathrm{Z}_{\max }$ & $\theta_{\max }$ & $\begin{array}{l}908 \text { confidence } \\
\text { limits }\end{array}$ \\
\hline$D 12 S 81$ & $-\infty$ & 3.71 & 4.61 & 4.87 & 4.60 & 3.66 & 2.48 & 1.12 & 0.04 & 4.88 & $0.001<\theta<0.18$ \\
\hline$D 12 S 319$ & $-\infty$ & 1.30 & 2.26 & 2.75 & 2.71 & 2.19 & 1.44 & 0.62 & 0.07 & 2.77 & $0.003<\theta<0.26$ \\
\hline$D 12 S 88$ & 0.64 & 0.81 & 1.40 & 1.91 & 1.97 & 1.67 & 1.14 & 0.54 & 0.09 & 1.98 & $0.002<\theta<0.33$ \\
\hline$D 12 S 365$ & 5.36 & 5.36 & 5.31 & 5.05 & 4.65 & 3.68 & 2.53 & 1.24 & 0.00 & 5.36 & $0.00<\theta<0.14$ \\
\hline$D 12 S 316$ & 1.44 & 1.70 & 2.39 & 2.89 & 2.89 & 2.40 & 1.58 & 0.60 & 0.07 & 2.93 & $0.002<\theta<0.27$ \\
\hline$D 12 S 82$ & 6.15 & 6.14 & 6.05 & 5.63 & 5.08 & 3.90 & 2.61 & 1.24 & 0.00 & 6.15 & $0.00<\theta<0.10$ \\
\hline$D 12 S 351$ & 6.20 & 6.19 & 6.10 & 5.69 & 5.16 & 4.00 & 2.72 & 1.35 & 0.00 & 6.20 & $0.00<\theta<0.10$ \\
\hline$D 12 S 322$ & 6.98 & 6.97 & 6.86 & 6.40 & 5.81 & 4.57 & 3.20 & 1.64 & 0.00 & 6.98 & $0.00<\theta<0.09$ \\
\hline$D 12 S 311$ & 4.95 & 4.94 & 4.88 & 4.60 & 4.18 & 3.22 & 2.10 & 0.95 & 0.00 & 4.95 & $0.00<\theta<0.13$ \\
\hline D12S95 & 2.89 & 2.89 & 2.88 & 2.79 & 2.60 & 2.09 & 1.47 & 0.76 & 0.00 & 2.89 & $0.00<\theta<0.24$ \\
\hline$D 12 S 327$ & $-\infty$ & -5.69 & -2.17 & 0.23 & 0.98 & 1.22 & 0.88 & 0.37 & 0.18 & 1.23 & $0.05<\theta<0.44$ \\
\hline$D 125309$ & $-\infty$ & -3.17 & -0.25 & 1.48 & 1.90 & 1.81 & 1.30 & 0.66 & 0.13 & 1.95 & $0.02<\theta<0.36$ \\
\hline
\end{tabular}

arbitrary starting point, the maximum multipoint lod score of 8.3 was reached at a map distance of $2.0 \mathrm{cM}$. The location corresponds to marker D12S82. Marker D12S351 is located $1 \mathrm{cM}$ telomeric to D12S82 and has an lod score almost as high, 7.8. As shown in Figure 1 the only remaining marker within a \pm 3 lod score interval is D12S311. This suggests the immediate vicinity of D12S82 and D12S351 as the best supported region for this dominant cornea plana gene. The

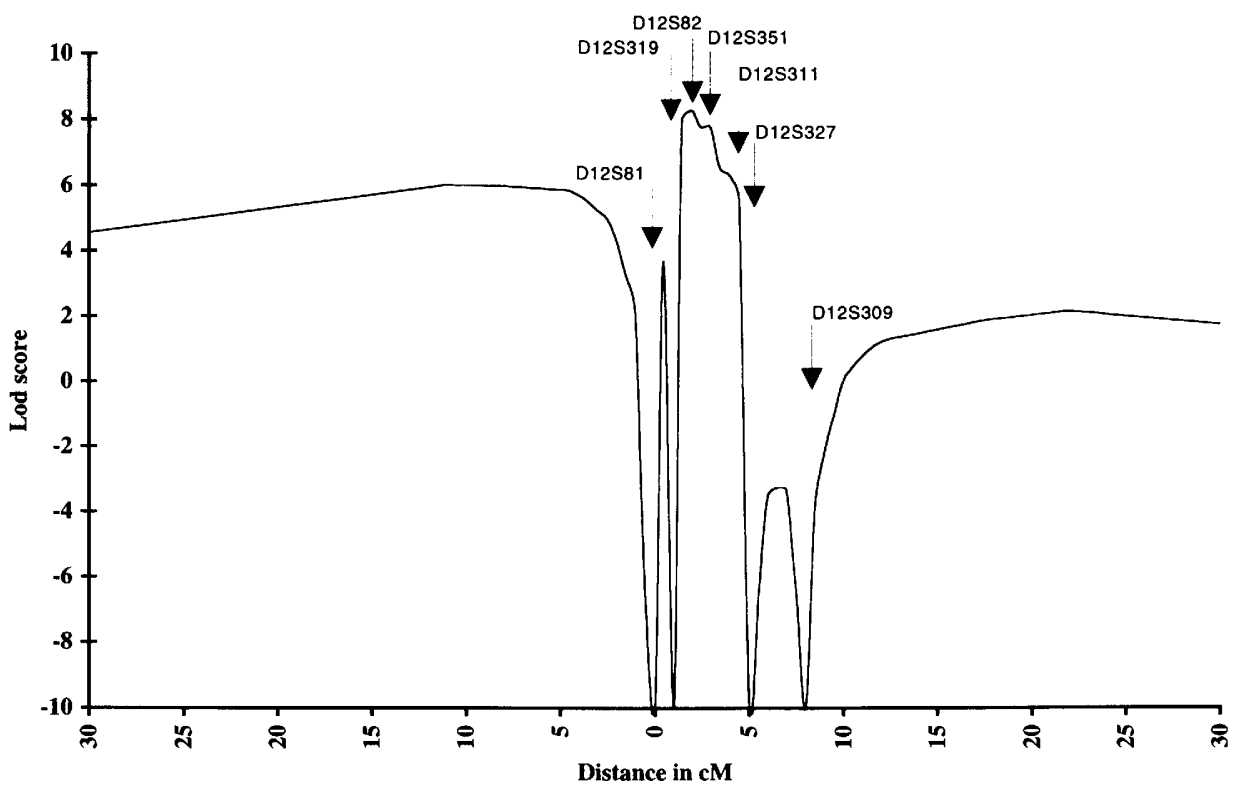

Figure 1 Eight-point linkage analysis between affection status and seven marker loci on chromosome 12 computed using the LINKMAP program. Marker D12581 was chosen as the starting point (zero). Sex-average distances based on Haldane map function are shown. The centromere is to the left. 


\section{CNAI AND CNA2 MAP IO THE SAME REGION OF CHROMOSOME 12}

recessive form of cornea plana was mapped previously to exactly the same location by linkage analysis; in addition, the highest value of linkage disequilibrium occurred with marker D12S351 (Tahvanainen et al. 1995b).

The result of haplotype analysis (Table 2) gives evidence of a single haplotype shared by all patients. In its best preserved core composed of markers D12S365, D12S316, D12S82, D12S351, D12S322, D12S311, and D12S95, the alleles are identical in all patients. Deviations from the most common haplotype occur at the more outlying loci. These delineate inferred historical recombinations reinforcing the most probable location of the disease gene between markers D12S88 and D12S327.

\section{DISCUSSION}

Our results show that mutation in a gene located in the long arm of chromosome 12 causes dominantly inherited cornea plana congenita in a $\mathrm{Cu}$ ban pedigree (Fig. 2). To our knowledge this is the largest cornea plana congenita pedigree reported thus far that shows unambiguous dominant transmission of the trait. The assignment was surprising as we recently had excluded this location by linkage studies in two Finnish CNA families also displaying dominant inheritance (Tahvanainen et al. 1996). Thus, a planned genomewide search for linkage in the Cuban family did not become necessary.

The genetic length of the critical interval harboring the CNA1 gene is somewhat smaller when derived from haplotype analysis than when deduced from obligatory recombinations detected by linkage analysis. This difference is attributable to the effects of deficient information provided by individuals in the pedigree with unconfirmed phenotype who were not available for genotyping. This result does not reflect a discrepancy between the two methods but raises the possibility that a disease chromosome may have been introduced into the pedigree more than once. Nonetheless, the results of the haplotype analysis are consistent with the hypothesis that one ancestral disease chromosome is shared by all affected individuals in this pedigree. This is a reasonable assumption in this rare disorder.

Somewhat surprisingly, these results document the existence of at least one recessively and two dominantly inherited forms of cornea plana. Earlier clinical descriptions are not necessarily at variance with this notion, in that they show

\section{Table 2. Disease Haplotypes for Each Affected Individual Constructed Assuming the Smallest Number of Recombinations}

\begin{tabular}{|c|c|c|c|c|c|c|c|c|c|c|c|c|}
\hline $\begin{array}{l}\text { Affected } \\
\text { Individual }\end{array}$ & $\begin{array}{l}\text { All } \\
81\end{array}$ & $\begin{array}{l}\mathrm{s} \text { at } \mathrm{n} \\
319\end{array}$ & $\begin{array}{r}\operatorname{arke} \\
88\end{array}$ & $\begin{array}{c}\operatorname{locus} D \\
365\end{array}$ & $\begin{array}{c}12 S \# \\
316\end{array}$ & 82 & 351 & 322 & 311 & 95 & 327 & 309 \\
\hline 1 & 8 & 8 & 6 & ND & 3 & 4 & 4 & 6 & 3 & 10 & 14 & 4 \\
\hline 2 & 8 & 8 & 6 & 1 & 3 & 4 & 4 & 6 & 3 & 10 & 5 & 3 \\
\hline 3 & 8 & 8 & 6 & 1 & 3 & 4 & 4 & 6 & 3 & 10 & 14 & 4 \\
\hline 4 & 8 & 8 & 6 & 1 & 3 & 4 & 4 & 6 & 3 & 10 & 5 & 3 \\
\hline 5 & 8 & 8 & 6 & 1 & 3 & 4 & 4 & 6 & 3 & 10 & 5 & 3 \\
\hline 6 & 8 & 8 & 6 & 1 & 3 & 4 & 4 & 6 & 3 & 10 & 5 & 3 \\
\hline 7 & 8 & 8 & 8 & 1 & 3 & 4 & 4 & 6 & 3 & 10 & 14 & 4 \\
\hline 8 & 8 & 8 & 6 & 1 & ND & 4 & 4 & 6 & 3 & 10 & 14 & 4 \\
\hline 9 & 8 & 8 & 8 & 1 & 3 & 4 & 4 & 6 & 3 & 10 & 14 & 4 \\
\hline 10 & 8 & 8 & 8 & 1 & 3 & 4 & 4 & 6 & 3 & 10 & 14 & 4 \\
\hline 11 & 8 & 8 & 6 & 1 & 3 & 4 & 4 & 6 & 3 & 10 & 5 & 3 \\
\hline 12 & 8 & 8 & 6 & 1 & 3 & 4 & 4 & 6 & 3 & 10 & 5 & 3 \\
\hline 13 & 8 & 8 & 6 & 1 & 3 & 4 & 4 & 6 & 3 & 10 & 5 & 3 \\
\hline 14 & 8 & 8 & 6 & 1 & 3 & 4 & 4 & 6 & 3 & 10 & 5 & 3 \\
\hline
\end{tabular}




\section{TAHVANAINEN ET AL.}

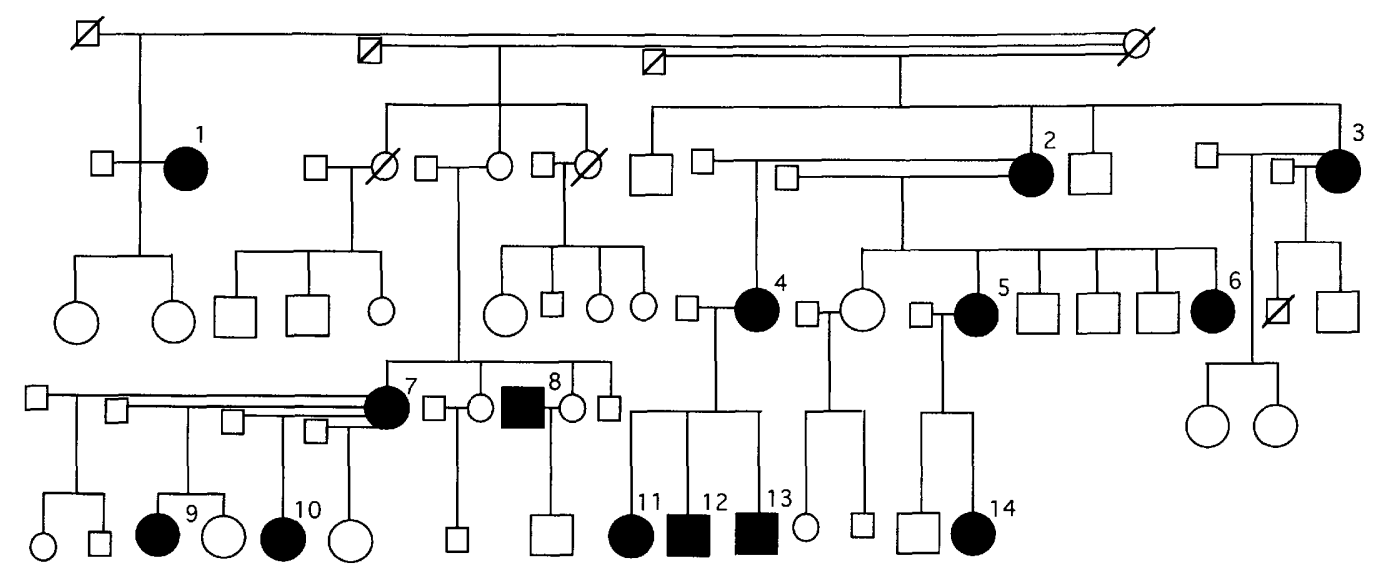

Figure 2 Pedigree of a four-generation family from Cuba displaying dominant cornea plana. To trim the size and display the study strategy, those individuals who were included in the linkage study are shown with larger symbols than the others. The absence of the cornea plana trait among those individuals who are marked with smaller symbols is not necessarily based on ophthalmologic examination in all cases. Those individuals were assigned disease status unknown in the linkage study. Numbers to the right of the symbol for each affected individual correspond to those shown in Table 2 .

marked variation in phenotype (Friede 1921; Kokott 1937; Larsen and Eriksen 1949; Eriksson et al. 1973; Ruprecht and Nauman 1974; Elliot et al. 1985). Two clinical types of cornea plana were suggested previously (Larsen and Eriksen 1949). Therefore, it is not entirely surprising that we found genetic heterogeneity in dominant cornea plana.

The most interesting of our findings is the colocalization of the loci for a dominantly and recessively inherited form of the "same" disease. Clearly this could be attributable to one of two alternative situations. Either both diseases are caused by mutations in the same gene or there are two or more genes adjacent to each other whose mutations can lead to a disturbance of corneal development.

The first hypothesis of one gene causing two disorders with different modes of inheritance is not without precedents. Examples of different mutations in one gene causing either dominant or recessive mode of inheritance include von Willebrand disease (Zhang et al. 1992), myotonia congenita (George et al. 1993; Lorenz et al. 1994), and epidermolysis bullosa (Christiano et al. 1993, 1994). Although the majority of mutations are recessive to wild type, the molecular mechanisms leading to a dominant mode of inheritance have been reviewed recently (Wilkie 1994). In short, the categories of dominant inheritance include alterations in gene dosage or protein activity, ectopic or temporally altered expression, domi- nant-negative effects, altered structural proteins, and toxic or new protein functions.

The second hypothesis of adjacent genes causing similar disorders may be even more likely, as there is abundant documentation of gene families or groups of genes that cluster in a chromosomal region and whose protein products have similar functions or participate in similar metabolic pathways. One example that might be relevant to cornea plana is the keratin gene cluster at 12q13 (Yoon et al. 1994). Keratin genes KRT3 and KRT12 encode the major keratins expressed in adult corneal epithelium in a number of species (Schermer et al. 1986; Kasper et al. 1988; Chaloin-Dufau et al. 1990). In the developing mouse eye KRT12 is first expressed at embryonic day 15 in corneal epithelium, later in all layers of the cornea, and at no stage in any other tissue than the cornea (Kurpacus et al. 1994). Neither the cytogenetic localization nor the nucleotide sequence of KRT12 (type I keratin) is known. Most of the genes for type I keratins are located on chromosome 17, but keratin 18 (KRT18) is located next to its partner keratin $8(K R T 8)$ in the chromosome 12 cluster. We are attempting to determine whether any keratin genes, especially $K R T 12$, might be located in the CNA region.

Determination of the molecular mechanisms leading to cornea plana requires the cloning of candidate genes in the disease region and the discovery of disease-causing mutations. Such work is in progress in our laboratory. 


\section{CNA1 AND CNA2 MAP TO THE SAME REGION OF CHROMOSOME 12}

\section{MATERIALS AND METHODS}

\section{Patients}

The patients were discovered and diagnosed in and around Moron City, Cuba. All patients belong to a four-generation pedigree (Fig. 2). Typical symptoms of dominant cornea plana observable in patients include reduced corneal curvature, hazy corneal limbus, and arcus lipoides. The corneal refraction of affected persons varies between 34.5 and 42.75 diopters (D), (mean in males $39.8 \mathrm{D}$, and in females $39.6 \mathrm{D})$ and the corneal diameter varies between 8.75 and $11.25 \mathrm{~mm}$ (mean in males $10.3 \mathrm{~mm}$, and in females 9.9 $\mathrm{mm}$ ). For comparison, in unaffected family members the mean corneal refraction is $43.6 \mathrm{D}$ in males and $44.2 \mathrm{D}$ in females and the mean horizontal diameter is $11.4 \mathrm{~mm}$ in males and $11.3 \mathrm{~mm}$ in females.

\section{Linkage and haplotype analysis}

Blood samples were collected from 14 affected persons and 16 unaffected relatives who were most relevant for linkage studies and who consented to take part in the study. DNA was isolated from blood leukocytes. The analyses were based on polymorphic markers from the Généthon collection (Gyapay et al. 1994) and published information on their order and distances. Allele numbering was based on the current on-line Genome Data Base version (Pearson 1991; Pearson et al. 1992; Cuticcia et al. 1993). The PCRs were done using published protocols (Weber et al. 1989). For linkage analyses the programs of the LINKAGE program package (Lathrop et al. 1984) were used. The $90 \%$ confidence limits shown in Table 1 are based on the \pm 1 lod unit method. For multipoint analysis marker genotypes were reduced to three-allele loci with equal allele frequencies. When several markers were reported without known intermarker distance and order, only the most informative marker from such a group was chosen for the multipoint analysis. As no significant sex difference was observed by CILINK analysis, sex-average recombination fractions were used in the construction of the multipoint map. All computations assumed dominant inheritance with complete penetrance. Haldane map function was used for the multipoint map. The disease allele frequency was arbitrarily set to 0.001. A LINKMAP analysis was carried out against a fixed map of four marker loci at the time in the order centromere-D12S81-D12S319-D12S82D12S351-D12S311-D12S327-D12S309-telomere with distances of $1,1,1,1,1$, and $3 \mathrm{cM}$, respectively, between the markers.

Likely haplotypes were constructed based on a minimum number of recombinations for those loci in which the haplotypes could not be determined by studying parents. The relative order of the four markers D12S319, D12S88, D12S365 and D12S316, and the three markers D12S311, D12S322, and D12S95 has not yet been determined by recombinational analysis in pedigrees from the Centre d'Etude du Polymorphisme Humain (Gyapay et al. 1994). This ambiguity was taken into account in the interpretation of the results.

\section{ACKNOWLEDGMENTS}

We thank Guillermo Mesa for help with the electronic communications, members and staff of the Ophthalmological Clinic of the Central Hospital of Moron City, and the cornea plana patients and their relatives who contributed to this study. Our special thanks go to Sinikka Lindh, R.N., for her devoted work in assisting in the clinical studies and the handling of the samples. Support from the Academy of Finland, The Finnish Medical Foundation, Alfred Kordelin Foundation, and the Finnish Foundation for Pediatric Research, Ulla Hjelt Fund is gratefully acknowledged.

The publication costs of this article were defrayed in part by payment of page charges. This article must therefore be hereby marked "advertisement" in accordance with 18 USC section 1734 solely to indicate this fact.

\section{REFERENCES}

Chaloin-Dufau, C., T.-T. Sun, and D. Dhouailly. 1990. Appearance of the keratin pair K3/K12 during embryonic and adult corneal epithelial differentiation in the chick and in the rabbit. Cell Differ. Dev. 32: 97-108.

Christiano, A.M., D.S. Greenspan, G.G. Hoffman, X. Zhang, Y. Tamai, A.N. Lin, H.C. Dietz, A. Hovnanian, and J. Uitto. 1993. A missence mutation in type VII collagen in two affected siblings with recessive dystrophic epidermolysis bullosa. Nature Genet. 4: 62-66.

Christiano, A.M., M. Ryynänen, and J. Uitto. 1994. Dominant dystrophic epidermolysis bullosa: Identification of a gly-to-ser substitution in the triple-helical domain of type VII collagen. Proc. Natl. Acad. Sci. 91: 3549-3553.

Cuticchia, A.J., K.H. Fasman, D.T. Kingsbury, R.J. Robbins, and P.L. Pearson. 1993. The GDB (TM) Human Genome Base Anno 1993. Nucleic Acids Res. 21: 3003-3006.

Elliot, J.H., S.S. Feman, D.M. O'Day, and M. Garber. 1985. Hereditary sclerocornea. Arch. Ophthalmol. 103: $676-679$.

Eriksson, A.W., W. Lehmann, and H. Forsius. 1973. Congenital cornea plana in Finland. Clin. Genet. 4: $301-310$.

Friede, R. 1921. Über kongenitale Cornea plana und ihr Verhältnis zur Mikrocornea. Klin. Mbl. Augenheilk. 79: $464-473$.

George, A.L. Jr, M.A. Crackower, J.A. Abdalla, A.J. Hudson, and G.C. Ebers. 1993. Molecular basis of Thomsen's disease (autosomal dominant myotonia congenita). Nature Genet. 3: 305-310.

Gyapay, G., J. Morissette, A. Vignal, C. Dib, C. Fizames, P. Millasseau, S. Marc, G. Bernardi, M. Lathrop, and J. Weissenbach. 1994. The 1993-94 Généthon human genetic linkage map. Nature Genet. 7: 246-339.

Kasper, M., R. Moll, P. Stosick, and U. Karsten. 1988. 


\section{TAHVANAINEN ET AL.}

Patterns of cytokeratin and vimentin expression in the human eye. Histochemistry 89: 369-377.

Kokott. 1937. Cornea plana und Mikrocornea peroplana. Klin. Mbl. Augenheilk. 98: 372-373.

Kurpakus, M.A., M.T. Maniaci, and M. Esco. 1994. Expression of keratins K12, K4 and K14 during development of ocular surface epithelium. 1994. Curr. Eye Res. 13: 805-814.

Larsen, V. and A. Eriksen. 1949. Cornea plana. Acta Ophthal. (Kbh.) 27: 275-286.

Lathrop, G.M., J.M. Lalouel, C. Julier, and J. Ott. 1984. Strategies for multilocus linkage analysis in humans. Proc. Natl. Acad. Sci. 81: 3443-3446.

Lorenz, C., C. Meyer-Kleine, K. Steinmeyer, M.C. Koch, and T.J. Jentsch. 1994. Genomic organization of the human muscle chloride channel CLC- 1 and analysis of novel mutations leading to Becker-type myotonia. Hum. Mol. Genet. 3: 941-946.

McKusick, V.A. 1994. Mendelian inheritance in man, 11th ed. Johns Hopkins University Press, Baltimore, MD.

Pearson, P.L. 1991. The Genome Data Base (GDB)-A human gene mapping repository. Nucleic Acids Res. (Suppl.) 19: 2237-2239.

Pearson, P.L., N.W. Matheson, D.C. Flescher, and R.J. Robbins. 1992. The GDB (TM) Human Genome Data Base Anno 1992. Nucleic Acids Res. (Suppl.)

20: 2201-2206.

Rübel, B. Kongenitale familiäre Flachheit der Kornea. 1912. Klin. Mbl. Augenheilk. 50: 427-433.

Ruprecht, K.W. and G. Naumann. 1974. Perforierende Keratoplastik und Histopathologie der Cornea plana. Klin. Mbl. Augenheilk. 165: 585-594.

Schermer, A., S. Galvin, and T.-T. Sun. 1986. Differentation-related expression of a major $64 \mathrm{~K}$ corneal keratin in vivo and in culture suggest limbal location of corneal epithelial stem cells. J. Cell Biol. 103: 49-62.

Tahvanainen, E., H. Forsius, E. Karila, S. Ranta, M. Eerola, J. Weissenbach, P. Sistonen, and A. de la Chapelle. 1995a. Cornea plana congenita gene assigned to the long arm of chromosome 12 by linkage analysis. Genomics 26: 290-293.

Tahvanainen, E., H. Forsius, M. Damsten, E. Karila, J. Kolehmainen, J. Weissenbach, P. Sistonen, and A. de la Chapelle. 1995b. Linkage-disequilibrium mapping of the cornea plana congenita gene. Genomics 30: 409-414.

Tahvanainen, E., H. Forsius, J. Kolehmainen, M. Damsten, J. Fellman, and A. de la Chapelle. 1996. The genetics of cornea plana congenita. J. Med. Genet. 33: $116-119$.
Weber, J.L. and P.E. May. 1989. Abundant class of human DNA polymorphisms which can be typed using the polymerase chain reaction. Am. J. Hum. Genet. 44: $388-396$.

Wilkie, A.O. 1994. The molecular basis of genetic dominance. J. Med. Genet. 31: 89-98.

Yoon, S.-J., J. LeBlanc-Straceski, D. Ward, K. Krauter, and R. Kucherlapati. 1994. Organization of the human keratin type II gene cluster at $12 \mathrm{q} 13$. Genomics 24: 502-508.

Zhang, Z.P., M. Lindstedt, G. Falk, M. Blombäck, N. Egberg, and M. Anvret. 1992. Nonsense mutations of the von Willebrand factor gene in patients with von Willebrand disease type III and type I. Am. J. Hum. Genet. 51: $850-858$.

Received November 28, 1995; accepted in revised form February 23, 1996. 


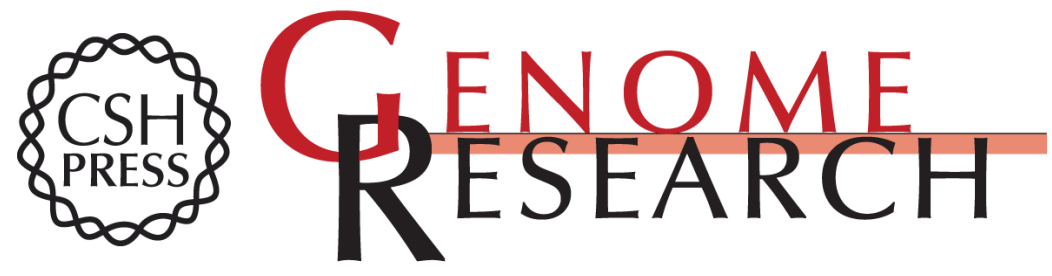

\section{Dominantly and recessively inherited cornea plana congenita map to the same small region of chromosome 12.}

E Tahvanainen, A S Villanueva, $\mathrm{H}$ Forsius, et al.

Genome Res. 1996 6: 249-254

Access the most recent version at doi:10.1101/gr.6.4.249

References This article cites 27 articles, 5 of which can be accessed free at:

http://genome.cshlp.org/content/6/4/249.full.html\#ref-list-1

\section{License}

Email Alerting Receive free email alerts when new articles cite this article - sign up in the box at the Service top right corner of the article or click here.

\section{Affordable, Accurate Sequencing.}

To subscribe to Genome Research go to:

https://genome.cshlp.org/subscriptions 